\title{
CONSTRUCTION AUTOMATION AND INTELLIGENT VEHICLE HIGHWAY SYSTEMS: COMMON THRUST AREAS
}

By: Raghavan Kunigahalli ${ }^{a}$, Jeffrey S. Russell ${ }^{b}$, and Miroslaw J. Skibniewski ${ }^{\mathrm{c}}$

a Sr. Res. Engr., Dept. of Civ. \& Env. Engrg., University of Wisconsin-Madison, Madison WI 53706.

b Assoc. Prof., Dept. of Civ. \& Env. Engrg., University of Wisconsin-Madison, Madison WI 53706.

c Assoc. Prof., School of Civ. Engrg., Purdue University, West Lafayette, IN 47907.

\begin{abstract}
:
Intelligent Vehicle Highway Systems are currently a high-priority area of research and development in many countries and can make significant improvements in mobility, safety, and productivity of transportation systems by utilizing advanced technologies from electronics, communications, and computer science. There are many research thrust areas that are useful to both IVHS and construction automation. This paper identifies a few common research thrust areas in IVHS that are applicable to development of automated construction systems. In particular, the following IVHS research areas applicable to construction automation and robotics are discussed: (1) traffic congestion characterization, (2) automated vehicle location, (3) electronic ticketing and automated trip payment, (4) vehicle guidance systems, and (5) safety and human factors.
\end{abstract}

\section{INTRODUCTION}

Each year more than 500,000 fatalities and 15 million injuries from traffic accidents are reported worldwide. Annual traffic accident costs, in the U.S. alone, is estimated to exceed $\$ 70$ billion. Further, current urban freeway delays in the U.S. is estimated at 2 billion vehicle hours per year and the annual loss of national productivity due to traffic delays from high-levels of congestion in the U.S. highways is estimated at $\$ 100$ billion $[1,2]$.

Intelligent Vehicle Highway Systems (IVHS), also called Intelligent Transportation Systems (ITS), focus on saving: (1) lives, (2) time, and (3) money due to traffic accidents and delays by employing advanced technologies from: (1) electronic communications, (2) information processing, and (3) automatic controls. IVHS, an integration of 
automation technology and road technology, not only improves safety, reduces congestion, enhances mobility, minimizes environmental impact, saves energy, and promotes economic productivity of road transportation systems but also can increase the attractiveness of public transportation [2]. It is estimated that, by the end of the next two decades, deployment of IVHS/ITS can: (1) reduce traffic congestion by 20 percent, (2) reduce traffic fatalities by up to 80 percent, and (3) increase road capacity by 300 percent [3].

The development of IVHS will have significant impact on the construction industry. The focus of the transportation facility sector of the construction industry will shift from the traditional construction methodologies to the area of electronics, communications, operations research, sensors, and robotics. The deployment of IVHS requires a multidisciplinary education of the construction professional that includes subjects such as: (1) information systems, (2) sensor technology, (3) motion planning, (4) communication systems, and (5) a variety of systems analysis [4]. This paper focuses on some common thrust areas of research applicable to both IVHS/ITS development and deployment and construction automation and robotics.

\section{INTERNATIONAL IVHS/ITS PROGRAMS}

A number of programs and substantial activities are underway in the U.S., Europe, and Japan. In May 1990, the Highway Users Federation of Safety and Mobility (HUFSAM) sponsored a National Leadership Conference in the U.S. on Implementing IVHS. Subsequently, the U.S. congress authorized \$660 million towards the IVHS program. In addition, a non-profit organization called the IVHS Society of America was formed as a forum to enhance the cooperation among the private and public members of the IVHS community and to speed up the implementation process. A number of IVHS/ITS implementation activities have already been initiated in the United States. The Smart Corridor, PATH, TravTek, and HELP Crescent projects are a few among them.

The two most important European IVHS programs are: (1) PROMETHEUS (Programme for European Traffic with Highest Efficiency and Unprecedented Safety), a EUREKA program and (2) DRIVE (Dedicated Road Infrastructure for Vehicle Safety in Europe), a European Community program. PROMETHEUS research initiative is expected to cost $\$ 800$ million and is a vehicle-oriented research program that deals mostly with issues related to enhancement of in-vehicle technologies. Safety is the raajor aspect of the PROMETHEUS program. It focuses on electronic driver-aids, vehicle-to-vehicle communications, and vehicle-to-road communications. On the other hand, DRIVE a $\$ 450$ million research program, is a traffic-management oriented program that focuses mostly on technologies for road infrastructure. DRIVE focuses on telematic services and systems, standardized technology, and common functional specifications [5].

The two major IVHS/ITS programs in Japan are: (1) Advanced Mobile Traffic Information and Communication System (AMTICS) and (2) Road-Automotive Communication System (RACS). AMTICS is sponsored by the National Police Agency and supported by the Ministry of Posts and Telecommunications. AMTICS transmits traffic-congestion information from a traffic control center to an in-vehicle display through a two-way digital circular communication system. 
RACS is a joint project involving the Ministry of Construction and 25 private firms. RACS focuses on: (1) real-time information collection at the traffic management center, (2) communication of information to roadside beacons, and (3) dissemination of information between road-side beacons and vehicles using microwave technology $[2,5]$.

\section{FUNCTIONAL AREAS OF IVHS/ITS}

The following five functional areas of IVHS/ITS have been identified by the IVHS Society of America:

- $\quad$ Advanced Traffic Management Systems (ATMS);

- Advanced Traveler Information Systems (ATIS);

- $\quad$ Advanced Vehicle Control Systems (AVCS);

- Commercial Vehicle Operations (CVO); and

- Advanced Public Transportation Systems (APTS).

A brief description of each of these functional areas is provided below.

ATMS are the basic building block of IVHS and involve detection/prediction, communication, and control of congestion in a given roadway system. ATMS provide alternative routing instructions to the vehicle operators based on the real-time information pertaining to traffic flow parameters such as speed, occupancy, and volume. The ATIS provide information to travelers in vehicles, at homes, in stores, and in offices. The ATIS utilize information from ATMS to generate: (1) locations of incidents, (2) weather and road conditions, (3) optimal routes, (4) recommended speeds, and (5) lane restrictions. The AVCS are aimed at enhancement of vehicle safety levels. AVCS will incorporate sensors to augment human eyes and ears and would alert the driver to an imminent collision. The AVCS can even make the vehicle automatically brake or steer away from an imminent collision.

The Commercial Vehicle Operations (CVO) systems utilize information generated by ATMS, ATIS, and AVCS to improve the safety and efficiency of commercial vehicle and fleet operations. CVO systems require advancement in technologies such as: (1) Automated Vehicle Location (AVL), (2) Automated Vehicle Classification, (3) Automated Vehicle Identification, (4) Dynamic Network Routing and (5) Weigh-In Motion (WIM). APTS are aimed at improving operational efficiency of high-occupancy vehicles. APTS enhance the accessibility of information to public transportation users and assist in the effective dispatching of buses, rail vehicles, and para-transit vehicles [2]. The next section identifies a few common research challenges pertaining to both IVHS and construction automation.

\section{COMMON THRUST AREAS}

\subsection{Traffic Congestion Characterization for ATMS and ATIS}

ATMS/ATIS require extraction of real-time information on the level of congestion in a given roadway system using localized information pertaining to traffic flow parameters generated by sensors located at various sections of the roadway system. A multidimensional geometric approach can be employed to solve this sensor integration problem [6]. Such an approach is also useful in developing efficient object-recognition 
methodologies for construction robotic vehicles such as autonomous dump truck systems [7].

A variant of the multi-dimensional approach that utilizes a well-known potential function can also be employed to characterize the congestion information on freeways [8]. The investigation of the potential function approach in a higher-dimensional space is very useful in solving multi-degree of freedom construction robot motion planning problems. However, mapping the problems into a higher-dimensional space and classification of different scenarios in that higher-dimensional space require in-depth research investigations.

\subsection{Automated Vehicle Location for APTS and CVO}

APTS/CVO require monitoring of transit and trucking fleets using Automatic Vehicle Location (AVL) systems. An AVL system is a computer-based vehicle tracking system that measures the actual position of each vehicle in real-time. The information on actual position is compared with its scheduled position and any deviation in these positions are reported to the dispatching center. Based on such information, dispatching centers can make appropriate modifications to the schedule and routes of the vehicles [9].

The computer-based vehicle tracking systems are extremely useful to monitor fleets of construction robots operating in uncertain environments. One such application has already been investigated by the researchers at the construction robotics unit of Tyndall Air Force Base, Florida. An Unmanned Ground Vehicle (UGV) to perform repair and removal process of Unexploded Ordnance (UXO) is being developed. A construction robotic vehicle navigation system for this UGV employs a differential Global Positioning System (GPS) to move autonomously from shelter to the clearance site and to position itself with an accuracy of \pm 6 inches [10].

\subsection{Electronic Ticketing and Automated Trip Payment}

Electronic ticketing refers to the automated ticket generation and fare collection process. Electronic ticketing and fare collection allows payment to be made without manual exchange of bills or coins. Electronic Ticketing and Automated Trip Payment requires advanced card technology with a programmable memory chip that can be used for identification, trip payment, and other travel-related functions [9].

The current practices of financial transactions within the construction industry relies heavily on paper-based exchanges in the form of cash, cheques, and invoices. Concepts from Electronic Ticketing and Automated Trip Payment can be extended to develop efficient project-card systems to handle financial transactions between various project participants in a given construction project. However, such a project-card based arrangement for financial transactions in the construction industry requires additional research work to develop programmable chips that can handle all possible financial transactions between various project participants.

\subsection{Vehicle Guidance System for AVCS and APTS}

Vehicle guidance systems for AVCS and APTS integrate longitudinal and lateral control mechanisms to ensure safe and smooth movement of vehicles. The following guidance strategies are commonly employed: (1) track guidance, (2) electronic guidance, (3) magnetic guidance, and (4) vision guidance [9]. Development of lateral control 
mechanisms poses a significant challenge in the area of: (1) supporting sensor technology and (2) control mechanisms. The complexity of this problem is aggravated due to the high-speed motion of vehicles on freeways.

Development of longitudinal and lateral control mechanisms for construction robots is extremely important to ensure accident-free Computer Integrated Construction (CIC) job-sites. Further, it is imperative for the successful implementation of both IVHS and CIC that advanced sensor technology be developed to support the motion control mechanisms that: (1) is reliable in dusty environment and (2) can be employed under allweather conditions.

\subsection{Safety and Human Factors}

IVHS/ITS generates abundant information used by travelers, drivers, traffic managers, and fleet managers. The information provided to the users must be effective and reliable so as to accomplish the goals and objectives of IVHS. Typically, information is provided to the users either through a visual display or through a voice message. Questions such as: (1) what information is needed, (2) how to present information, (3) how to provide warning, (4) how to provide control assistance, (5) how to get responses from the user, and (6) how to incorporate differences in the behavior of the users need to be addressed carefully while designing a visual display/control or voice message system [2].

Answers to such questions require advanced research work in the area of human factors and ergonomics. These questions play equally important roles even in the case of automated equipment to perform construction processes. For example, consider warning display due to malfunctioning of a small unit in a computer-controlled slurry wall construction system [11]. Different operators/construction technicians can react differently for the same warning situation. Even the same operator may react differently in different situations to the same warning display. Hence, to promote safety on Computer Integrated Construction (CIC) job-sites, such visual displays for computercontrolled systems must be carefully designed.

\section{SUMMARY}

An overview of Intelligent Vehicle Highway Systems (IVHS) was provided. A few ongoing IVHS research programs in the U.S., Europe, and Japan were enumerated. Five functional areas of IVHS/ITS identified by IVHS/ITS America were briefly described. A few thrust areas of research and development that are useful to both IVHS and construction automation were identified.

\section{ACKNOWLEDGEMENTS}

The authors wish to thank the National Science Foundation for Grant No. MSM9058092, Presidential Young Investigator Award, for financial support of this effort. 


\section{REFERENCES}

[1] Wilson, C., and Burtch, T. M., (1992). "Traffic Accidents and Highway Safety." Traffic Engineering Handbook, Pline, J. L. (ed.), Prentice Hall, Englewood Cliffs, NJ, USA.

[2] IVHS-America, (1992). "Strategic Plan for Intelligent Vehicle-Highway Systems in the United States," Intelligent Vehicle-Highway Society of America, Washington, D.C., USA.

[3] Constantino, J., "Smart Transportation: Poised to Change the Way America Travels," Transportation Builder, May 1994, pp. 18-20.

[4] Sussman, J. M., (1993). "Intelligent Vehicle Highway Systems," Construction Business Review, May/June 1993, pp. 60-65.

[5] Euler, G. W., (1992). "Intelligent Vehicle-Highway Systems," Traffic Engineering Handbook, Pline, J. L. (ed.), Prentice Hall, Englewood Cliffs, NJ, USA.

[6] Kunigahalli, R., (1995). "A Multi-Dimensional Geometric Approach to Freeway Congestion Detection," Proceedings of Fifth Annual Meeting of IVHS/ITS America, March 15-17, Washington, D.C., USA.

[7] Sugiura, H., Yute, S., Nishide, K., Hatekeyama, O., and Nishigaki, S., (1993). "Autonomous Dump Truck Systems for Transporting and Positioning Heavy-Duty Materials in Heavy Construction Sites," Proceedings of the Tenth International Conference on Automation and Robotics in Construction, May 24-26, Houston, Texas, USA, pp. 253-260.

[8] Kunigahalli, R. and Russell, J. S., (1995). "Traffic Congestion Characterization from Supervised Learning," Proceedings of Sixth International Conference on Computing in Civil and Building Engineering, Berlin, July 12-15, 1995.

[9] Schweiger, C. L., Kihl, M., and Lebell, L. N., (1994). "Advanced Public Transportation Systems: The State of the Art," USDOT Report Number FTA-MA26-0007-94-1, National Technical Information Service, Springfield, VA, USA.

[10] Nease, A. D. and Alexander, E. F., (1993). "Air-Force Construction Automation/Robotics," Proceedings of the Tenth International Conference on Automation and Robotics in Construction, May 24-26, Houston, Texas, USA, pp. 341-346.

[11] Nakamura, T. and Tsuchiya, K., (1988). "The Computer-Controlled System for Deep Slurry Wall Construction," Proceedings of the Fifth International Conference on Robotics in Construction, June 6-8, Tokyo, Japan, pp. 695-701. 